\title{
DCOBS: Forecasting the Term Structure of Interest Rates with Dynamic Constrained Smoothing B-Splines
}

\author{
Eduardo Phillipe Mineo
}

DISSERTATION PRESENTED

TO THE

Institute of Mathematics And Statistics

OF THE

University of SÃo PAUlo

$\mathrm{TO}$

Fulfill the Requirements of the Degree

$\mathrm{OF}$

MASTER IN SCIENCE

Program: Applied Mathematics

Supervisor: Prof. Dr. Antonio Elias Fabris 


\section{DCOBS: Forecasting the Term Structure of Interest Rates with Dynamic Constrained Smoothing B-Splines}

\footnotetext{
This version of the dissertation contains corrections and modifications suggested by the Examining Board during the defense of the original version of the work happened in 01/12/2017. A copy of the original version is available at the Institute of Mathematics and Statistics of the University of São Paulo.
}

Comissão Julgadora:

- Prof. Dr. Antonio Elias Fabris - IME-USP

- Prof ${ }^{a}$. Dra ${ }^{a}$. Airlane Pereira Alencar - IME-USP

- Prof. Dr. Marcelo Moura 


\section{Acknowledgements}

I dedicate this work to my sweet wife, Vanessa and my beloved parents José Roberto and Dalva. I am deeply grateful to my tutors Prof. Dr. Antonio Elias Fabris, Prof. Dr. Marcelo Moura and Prof $^{\mathrm{a}}$. Dr ${ }^{\mathrm{a}}$. Airlane Pereira Alencar, for believing in me and for sharing so much wisdom with so much patience. Finally, my most sincere thanks to IME-USP and all its staff that have welcomed me with open arms. 


\section{Abstract}

MINEO, E. P. DCOBS: Forecasting the Term Structure of Interest Rates with Dynamic Constrained Smoothing B-Splines. 2017. 66 f. Dissertation (M.Sc.) - Instituto de Matemática e Estatística, Universidade de São Paulo, São Paulo, 2017.

The Nelson-Siegel framework published by Diebold and Li a decade ago created an important benchmark and originated several works in the literature of forecasting term structure of interest rates. For instance, the Arbitrage-Free Nelson-Siegel framework improved predictive performance by imposing no-arbitrage conditions to the Nelson-Siegel framework. However, these frameworks were built on the top of a parametric curve model that may lead to poor fitting for sensible term structure shapes affecting forecast results. We propose DCOBS with no-arbitrage restrictions to forecast the term structure. It is built on the top of the nonparametric constrained smoothing Bsplines yield curve model. This curve model has shown to be an optimum solution between financial integrity and respect to yield curve shapes. Even though this curve model may provide more volatile forward curves than parametric models, they are still more accurate than those from Nelson-Siegel frameworks. A software was developed with a complete implementation of yield curve fitting techniques discussed in this paper. DCOBS has been evaluated for ten years of brazilian government bond data and it has shown good consistence with stylized facts of yield curves. The results of DCOBS are promising, specially in short-term forecast, and has shown greater stability and lower root mean square errors than Arbitrage-Free Nelson-Siegel.

Keywords: numerical analysis, B-splines, time-series, term structure, interest rates, no-arbitrage, brazilian bonds. 


\section{Resumo}

MINEO, E. P. DCOBS: Previsão da Estrutura a Termo de Taxa de Juros com B-Splines restritas, suavizadas e dinâmicas. 2017. 66 f. Dissertação (Mestrado) - Instituto de Matemática e Estatística, Universidade de São Paulo, São Paulo, 2017.

O framework Nelson-Siegel publicado por Diebold e Li uma década atrás criou um importante benchmark e originou diversos trabalhos na literatura de previsão de estrutura a termo de taxas de juros. Por exemplo, o framework Nelson-Siegel Livre de Arbitragem melhorou a performance preditiva impondo condições de não-arbitragem ao framework Nelson-Siegel. No entanto, estes frameworks foram construídos em cima do modelo de curvas paramétricas. Em casos mais sensíveis de formas de curvas, este modelo tem um desempenho muito ruim, afetando o resultado da previsão. Nós propomos o DCOBS com restrições de não-arbitragem para prever a estrutura a termo. Ele é construído em cima do modelo de curva não-paramétrico com B-Splines restritas e suavizadas. Este modelo demonstrou ser uma solução ótima entre integridade financeira e respeito às formas de curvas de juros. Embora este modelo de curva possa resultar em curvas forwards mais voláteis que os modelos paramétricos, ele é ainda mais acurado que aqueles do framework Nelson-Siegel. Um software foi desenvolvido com uma implementação completa das técnicas de ajustes de curvas de juros discutidas nesta dissertação. DCOBS foi avaliado utilizando dez anos de dados de títulos públicos do governo brasileiro e demonstrou boa consistência com os fatos estilizados das curvas de juros. Os resultados do DCOBS são promissores, especialmente na previsão de curto prazo, e demonstrou maior estabilidade e menor erro quadrático médio que o modelo Nelson-Siegel Livre de Arbitragem.

Palavras-chave: análise numérica, B-splines, séries-temporais, estrutura a termo, taxa de juros, não-arbitragem, títulos públicos. 


\section{Contents}

$\begin{array}{ll}\text { List of abbreviations } & \text { ix }\end{array}$

List of Figures $\quad$ xi

List of Tables $\quad$ xiii

1 Introduction $\quad 1$

2 Yield curve models $\quad 5$

2.1 Term structure of interest rates . . . . . . . . . . . . . . . . . 5

2.2 Dynamic Nelson-Siegel . . . . . . . . . . . . . . . . . . . . . . 6

2.3 Arbitrage-Free Nelson-Siegel . . . . . . . . . . . . . . . . . . 7

3 Dynamic Constrained Smoothing B-splines 11

4 Descriptive Analysis $\quad 15$

$\begin{array}{llr}5 & \text { Results } & 17\end{array}$

6 Conclusion $\quad 23$

$\begin{array}{ll}\text { Bibliography } & 25\end{array}$ 
viii CONTENTS 


\title{
List of abbreviations
}

\author{
DCOBS Dynamic Constrained Smoothing B-Splines \\ NS Nelson-Siegel \\ DNS Dynamic Nelson-Siegel \\ AFNS Arbitrage-Free Nelson-Siegel \\ RMSE Root Mean Square Error \\ GCV Generalized Cross Validation
}




\section{List of Figures}

3.1 Yield curves for term structure at $2009-10-20 \ldots \ldots \ldots \ldots \ldots$

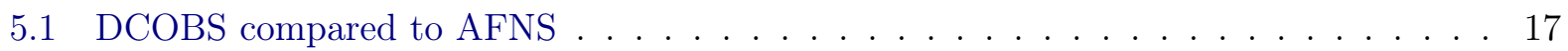

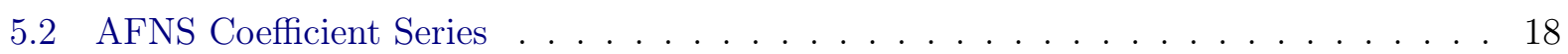

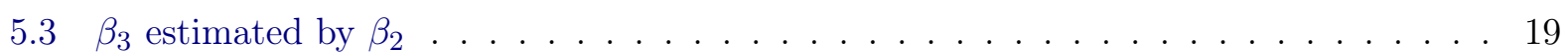

5.4 AFNS coefficient time series . . . . . . . . . . . . . . . . . . . . . . 19

5.5 DCOBS Coefficient Series . . . . . . . . . . . . . . . . . 20

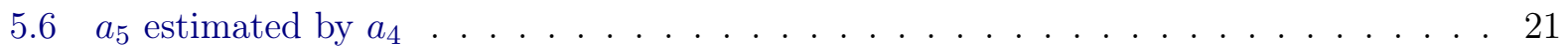

5.7 DCOBS coefficient time series . . . . . . . . . . . . . . . . 21

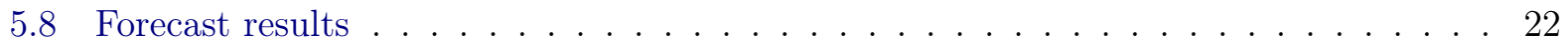




\section{List of Tables}

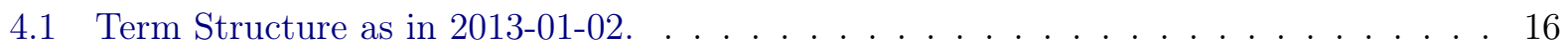

4.2 Term structure with yields at the boundaries. . . . . . . . . . . . . . 16

4.3 Normalized term structure. . . . . . . . . . . . . . . . . . . 16

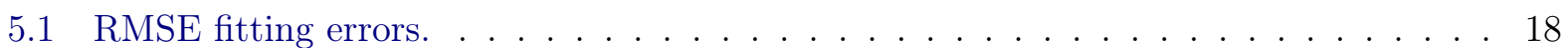

5.2 AFNS ADF Test for coefficients . . . . . . . . . . . . . . . . . . 18

5.3 DCOBS ADF Test for coefficients . . . . . . . . . . . . . . . . . 20

5.4 Forecast root mean square errors . . . . . . . . . . . . . . . . . . 22

5.5 Diebold-Mariano Test Statistics . . . . . . . . . . . . . . . . . . . . . 22 


\section{Chapter 1}

\section{Introduction}

Forecast methods applied to term structure of interest rates are important tools not only for banks and financial firms, or governments and policy makers, but for society itself, helping to understand the movements of markets and flows of money. Several works have been done during the past decades in order to predict the dynamics of term structure of interest rates. This paper presents a dynamic version of constrained smoothing B-splines model to forecast the yield curve with no-arbitrage restrictions.

A complete term structure of interest rates does not exist in the real world. Observable market data are discrete points that relate interest rates to maturity dates. Since it is unlikely that there will be an available contract in the market for every maturity needed by practitioners, a continuous curve model is necessary. The importance of these models is crucial for pricing securities, for instance. The first modeling technique that comes to mind is interpolation. With interpolation one can indeed obtain an adherent fit, but it can easily lead to unstable curves since market data is subject to many sources of disturbance.

The literature describes two approaches for estimating the term structure of interest rates: a statistical approach and an equilibrium approach. The equilibrium approach makes use of theories that describe the overall economy in terms of state variables and its implications on short-term interest rates. In the statistical approach, the construction of the yield curve relies on data observed in the market. This observed data can be smoothed with parametric or nonparametric methods. Parametric methods have functional forms and its parameters can have economic interpretations such as Nelson-Siegel [NS87] model or Svensson [Sve94] model. One advantage is that restrictions on parameters can be added so it copes with convenient economic theories such as the arbitrage-free set. However, its functional form makes parametric methods less flexible to fit observed data. This lack of adherence to data can make its practical usage inappropriate, specially in asset pricing and no-arbitrage applications due to misspecification [LM10]. The model can produce yield curves with theoretical integrity but without reflecting the reality. On the other hand, nonparametric methods do not assume any particular functional form and consequently they are very flexible and can be very robust if combined with appropriate conditions.

After 40 years since the publication of the first yield curve models, just recently the yield curve dynamics became an essential topic. With the publication of the Dynamic Nelson-Siegel (DNS) model by Diebold and Li [DL03], the subject became established. Even though the dynamics of term structure play a vital role in macroeconomic studies, Diebold and Li argued that until then little attention had been paid to forecasting term structures. They gave two reasons for this lack of interest. Firstly, they stated that no-arbitrage models had little to say about term structure dynamics. Secondly, based on the work of Duffee [Duf02], they assumed that affine equilibrium models ${ }^{1}$ forecast poorly. Therefore, there was a belief that dynamics of yield curve could not be forecast with parsimonious models.

In order to challenge this idea, Diebold and Li proposed the DNS model using Nelson-Siegel

\footnotetext{
${ }^{1}$ The expression "affine term structure model" describes any arbitrage-free model in which bond yields are affine (constant-plus-linear) functions of some state vector x. For further reading, we recommend [Pia10].
} 
yield curve fitting to forecast its dynamics. This model became very popular among financial market users and even central banks around the world. It is parsimonious and stable. Also, Nelson-Siegel functional imposes some desired economic properties such as discount function approaching zero as maturity evolves and its factors representing short, medium and long term behavior.

In practice, the forecast results of DNS are remarkable, but despite its both theoretical and empirical success, DNS did not consider restrictions for arbitrage opportunities. Practitioners could be exposed to critical financial risks, as the pricing of assets that depends on interest rates relies on arbitrage-free theory. In order to mitigate these risks, Christensen et al. [CDR11] introduce a class of Arbitrage-Free Nelson-Siegel (AFNS) models. They were affine term structure models that keep the DNS structure and incorporate no-arbitrage restrictions. Tourrucôo et al [TCMS16] list several appealing features of AFNS. They keep the desired economic properties of the three-factors model of the original structure of DNS. They also ensure lack of arbitrage opportunities with a more simple structure compared to those affine arbitrage-free models published previously by Duffie and Kan [DK96] and Duffee [Duf02]. This is achieved by adding a yield-adjustment term to Nelson-Siegel yield curve model described as an ordinary differential system of equations to ensure no-arbitrage. Tourrucôo et al [TCMS16] argues that, in long forecast horizons, AFNS model with uncorrelated factors delivers most accurate forecasts. Their conclusion is that no-arbitrage is indeed helpful, but only for longer forecasting horizons.

Barzanti and Corradi [BC01] published earlier works on the use of constrained smoothing Bsplines to estimate term structures of interest rates. But Laurini and Moura [LM10] proposed constrained smoothing B-splines with a different methodology. This methodology was initially proposed by He and Shi [HS98] and He and Ng [HN99] as a general tool to smooth data with certain qualitative properties such as monotonicity and concavity or convexity constraints. Roughly, the methodology builds the yield curve as a $L_{1}$ projection of a smooth function into the space of Bsplines. It is achieved by estimating a conditional median function as described in quantile regression theory of Koenker and Basset [KB78]. A great advantage is that, being a conditional median function, it is robust to outliers. Also, its formulation as a linear programming problem gives us the ability to impose several constraints without substantial increase in computational costs.

Our present work proposes a dynamic constrained smoothing B-splines (DCOBS) model to forecast the term structure of interest rates. DCOBS describes the coefficients of the yield curve model proposed by Laurini and Moura[LM10] as processes evolving over time. Even though constrained smoothing B-splines specification provides full automation in knot mesh selection, we could not use it in a dynamic framework setting. In order to build a common ground and observe curve shapes evolving over time, knots were fixed to capture short, medium and long term behavior according to observed data. These knots were adjusted equally in the dataset, so there was the same amount of coefficients on each daily curve and it was possible to run a statistical regression. DCOBS has shown great predictability in short-term, and remained stable on the long-term.

In Chapter 2 we give a brief introduction to the fundamental theories of dynamic Nelson-Siegel models. In Chapter 3 we introduce DCOBS model. In Chapter 4 we present the data set used for fitting and forecasting the brazilian term structure of interest rates. In Chapter 5 we study the outputs from time series of fitted yield curves. Finally, in Chapter 6 we finish the work pointing the conclusions we made.

The main contribution of this work are:

- A complete formulation of no-arbitrage constrained smoothing B-splines in terms of objective functions and linear constraint equations;

- A dynamic framework of constrained smoothing B-splines described as AR(1) processes (DCOBS);

- Evaluation of DCOBS framework compared to AFNS for ten years of brazilian government bonds data;

- Automatic selection of the best smoothing parameter $\lambda$ for fitting yield curves;

- Yield curves estimated as conditional median functions robust to outliers; 
- Yield curves with better adherence to data compared to Nelson-Sielgel family curves.

- A software that fits several curve fitting models, including no-arbitrage constrained smoothing B-splines; 


\section{Chapter 2}

\section{Yield curve models}

\subsection{Term structure of interest rates}

We will treat interest rates as a multidimensional variable that represents the return on investment expressed by three related information: spot rate, forward rate and the discount value.

Each of these values depends on several economical, political and social informations, such as supply and demand of money and the expectation of its future value, risk and trust perception, consequences of political acts, etc. The term structure of interest rates is a valuable tool not only for banks and financial firms, or governments and policy makers, but for society itself, helping to understand the movements of markets and flows of money.

We will assume that fixed income government bonds can be considered risk-free so we can define a special type of yield that is the spot interest rate, $s(\tau)$. This function is the return of a fixed income zero-coupon risk-free bond that expires in $\tau$ periods. Today's price of such financial instrument whose future value is $\$ 1.00$ and its interest rate is continuously compounded is given by the discount function, $d(\tau)$, represented by

$$
d(\tau)=e^{-s(\tau) \times \tau}
$$

The Equation 2.1 establishes the relationship between the discount value and the spot rate, which can be recovered by

$$
s(\tau)=-\frac{\log (d(\tau))}{\tau} .
$$

Based on the available bonds in the market with different maturities, it is possible to plan now a financial transaction that will take place in the future, starting at the maturity of the shorter bond and expiring at the maturity of the longer bond.

The interest rate of this future transaction is called the forward rate.

Consider a forward contract traded at the present day at $\tau_{P}=0$. This contract arranges an investment in the future that starts at the settlement date at time $\tau$. This investment will be kept until the maturity date, at time $\tau_{M}>\tau$. Then, the continuously compounded (implied) forward rate is related to the spot rate according to

$$
f\left(\tau, \tau_{M}\right)=\frac{s\left(\tau_{M}\right) \times \tau_{M}-s(\tau) \times \tau}{\tau_{M}-\tau} .
$$

If we take the limit of $\tau_{M} \rightarrow \tau$, we end up with the instantaneous forward rate or short rate. The short rate is the forward rate for a forward contract with an infinitesimal investment period after the settlement date, and it is defined as

$$
f(\tau)=\lim _{\tau_{M} \rightarrow \tau} f\left(\tau, \tau_{M}\right) .
$$

The forward rate can be seen as the marginal increase in the total return from a marginal increase 
in the length of the investment [Sve94]. The spot rate $s(\tau)$ is identical to the average of the instantaneous forward rates with settlement between the trade date 0 and the maturity date $\tau$ whose formulation is defined as

$$
s(\tau)=\frac{1}{\tau} \int_{0}^{\tau} f(x) \mathrm{d} x .
$$

From Equation 2.1 and Equation 2.2 we can relate the discount function and forward rate as

$$
d(\tau)=e^{-\int_{0}^{\tau} f(x) \mathrm{d} x}
$$

and

$$
f(\tau)=-\frac{d^{\prime}(\tau)}{d(\tau)}
$$

The relationship between the yields of bonds that differ only by their term to maturity gives us a function called yield curve. The relationship between spot rates of bonds that differ only in their term to maturity is called term structure of interest rates [CIR85].

Yield curves for coupon-bearing bonds should not be used as direct representations of the term structure of interest rates, since yield curves of coupon-bearing bonds are not equivalent of the yield curves of zero-coupon bonds with same maturity dates[Sve94].

On the other hand, yield curves of zero-coupon bonds are equivalent to their spot rates curve, from now on called term structure of interest rates.

Since there is no continuous term structure of interest rates in real world ${ }^{1}$, a curve is estimated by mathematical models in order to represent the term structure of interest rates in a continuous way, providing a valuable tool to calculate the spot rate at any instant within a given interval.

As pointed by Diebold and Li[DL03], the classical approaches to model the term structure of interest rates are equilibrium models and no-arbitrage models.

Equilibrium models derive the term structure of interest rates from economic variables to model a stochastic process for the short rate dynamic, typically using affine models, after which spot rates can be derived under some risk premium assumptions. Examples of equilibium models are [Vas77], [CIR85] and [DK96].

On the other hand, no-arbitrage models focuses on perfectly fitting the term structure of interest rate on observed market spot rates in such a way that there is no arbitrage opportunity. Major contribution to no-arbitrage models were give by [HW90] and [HJM92].

In the work of Diebold and Li[DL03], neither the equilibrium model nor the no-arbitrage model are used to model the term structure of interest rates. Instead, they use the Nelson and Siegel [NS87] exponential components framework because they claimed that this model produces encouraging results for out-of-sample forecasting, and until that time, little attention in literature of no-arbitrage and equilibrium models had been paid to dynamics and forecasting of interest rates.

\subsection{Dynamic Nelson-Siegel}

Diebold and Li proposed a dynamic version of Nelson-Siegel yield curve model

$$
N S(\tau)=\beta_{1} L_{1}(\tau)+\beta_{2} L_{2}(\tau)+\beta_{3} L_{3}(\tau) .
$$

There are several contracts available in the market each day. So, a yield curve is fitted according to Nelson-Siegel model to relate yields and maturities of available contracts for a specific day. We will refer to it as the Nelson-Siegel static model for yield curves. The curves are fitted by constructing a least squares program such that $\theta=\left\{\beta_{1}, \beta_{2}, \beta_{3}\right\}$ are the parameters that minimize the distance between $N S(\tau)$ and market data points. The coefficients $\beta_{1}, \beta_{2}, \beta_{3}$ are interpreted as three latent dynamic factors. The loading on $\beta_{1}$ is constant and do not change in the limit, then $\beta_{1}$ can be viewed as a long term factor. The loading on $\beta_{2}$ starts at 1 and decay quickly to zero, then $\beta_{2}$ can

\footnotetext{
${ }^{1}$ Spot rates are discrete points observed in contracts available in the market
} 
be viewed as a short term factor. Finally, the loading on $\beta_{3}$ starts at zero, increases and decay back to zero, then $\beta_{3}$ can be viewed as a medium term factor.

The Dynamic Nelson-Siegel model for forecasting the yield curve $s(\tau)$ describes the static model evolving over time. The Dynamic Nelson-Siegel model is

$$
\begin{aligned}
s_{t}(\tau) & =\beta_{1, t} L_{1}(\tau)+\beta_{2, t} L_{2}(\tau)+\beta_{3, t} L_{3}(\tau)+\epsilon_{t} \\
t & =1, \ldots, T
\end{aligned}
$$

where

$$
\begin{aligned}
& L_{1}(\tau)=1, \\
& L_{2}(\tau)=\frac{1-e^{-\lambda \tau}}{\lambda \tau}, \\
& L_{3}(\tau)=\frac{1-e^{-\lambda \tau}}{\lambda \tau}-e^{-\lambda \tau} .
\end{aligned}
$$

The parameter $\lambda$ is a constant interpreted as the conductor of the curve exponential decay rate and the coefficients $\beta_{i, t}$ are $\operatorname{AR}(1)$ processes described as

$$
\beta_{i, t}=c_{i}+\phi_{i} \beta_{i, t-1}+\eta_{i, t} \quad i=1,2,3
$$

where the intercepts $c_{i}$, the parameters $\phi_{i}$ and the coefficients $\beta_{i, t}$ are obtained fitting the model over a dataset of $T$ daily market observations. Furthermore, $\epsilon_{t} \sim \mathcal{N}\left(0, \sigma_{\epsilon}^{2}\right)$ and $\eta_{i, t} \sim \mathcal{N}\left(0, \sigma_{i}^{2}\right)$ are independent errors. Since the yield curve model depends only on $\beta_{1, t}, \beta_{2, t}, \beta_{3, t}$, forecasting the yield curve is equivalent to forecasting $\beta_{1, t}, \beta_{2, t}, \beta_{3, t}$.

Conversely, the factors for long-term, short-term and medium-term can also be interpreted in terms of level, slope and curvature of the model. Diebold and Li [DL03] use these interpretations to claim that the historical stylized facts of the term structure of interest rates can be replicated by fitting the three factors, which means that the model can replicate yield curve geometric shapes.

$N S(\tau)$ also correspond to a discount curve, transformed according to Equation 2.1, that begins at one for zero maturity and approaches zero as maturity goes to infinity.

For US market, [DL03] shows that DNS model outperforms traditional benchmarks such as the random walk model, even though Vicente et al.[VVT08] states that the model does not outperform random walk forecast for short-term forecasts (one-month ahead).

\subsection{Arbitrage-Free Nelson-Siegel}

Arbitrage-Free Nelson-Siegel static model for daily yield curve fitting was derived by Christensen et al.[CDR11] from the standard continuous-time affine Arbitrage-Free formulation of Duffie and $\operatorname{Kan}[\mathrm{DK} 96]$. Let be a filtered probability space $\left(\Omega, \mathcal{F},\left(\mathcal{F}_{\tau}\right), Q\right)$, where the filtration $\left(\mathcal{F}_{\tau}\right)=\left\{\mathcal{F}_{\tau}\right.$ : $\tau \geq 0\}$ satisfies the usual conditions. Also, consider the state variable $X_{\tau}$ assumed to be a Markov Process defined on a set $M \subset \mathbf{R}^{n}$ that solves the stochastic differential equation

$$
d X_{\tau}=K^{Q}(\tau)\left[\Theta^{Q}(\tau)-X_{\tau}\right] d \tau+\Sigma(\tau) D\left(X_{\tau}, \tau\right) d W_{\tau}^{Q},
$$

where $W^{Q}$ is a standard Brownian motion in $\mathbf{R}^{n}$ in respect to the filtration $\left(\mathcal{F}_{\tau}\right)$. The drifts $\Theta^{Q}:\left[0, \tau_{M}\right] \rightarrow \mathbf{R}^{n}$, dynamics $K^{Q}:\left[0, \tau_{M}\right] \rightarrow \mathbf{R}^{n \times n}$ and volatility matrix $\Sigma:\left[0, \tau_{M}\right] \rightarrow \mathbf{R}^{n \times n}$ are bounded continuous functions. Also, $D: M \times\left[0, \tau_{M}\right] \rightarrow \mathbf{R}^{n \times n}$ has diagonal structure with entries

$$
[D]_{i i}=\sqrt{\gamma^{i}(\tau)+\delta_{1}^{i}(\tau) X_{\tau}^{1}+\cdots+\delta_{n}^{i}(\tau) X_{\tau}^{n}} \quad \forall i \in\{1, \ldots, n\}
$$


where $\gamma^{i}:\left[0, \tau_{M}\right] \rightarrow \mathbf{R}^{n}$ and $\delta^{i}:\left[0, \tau_{M}\right] \rightarrow \mathbf{R}^{n \times n}$ are bounded continuous functions. We will consider the instantaneous risk-free rate as an affine function of the state variables

$$
r_{\tau}=\rho_{0}(\tau)+\rho_{1}(\tau)^{\prime} X_{\tau}
$$

where $\rho_{0}:\left[0, \tau_{M}\right] \rightarrow \mathbf{R}$ and $\rho_{1}:\left[0, \tau_{M}\right] \rightarrow \mathbf{R}^{n}$ are bounded continuous functions.

Duffie and Kan [DK96] demonstrated that zero-coupon bound prices could be formulated with the previous framework as exponential affine functions of the state variables

$$
P\left(\tau, \tau_{M}\right)=E_{\tau}^{Q}\left[\exp \left(-\int_{\tau}^{\tau_{M}} r_{u} d u\right)\right]=\exp \left(B\left(\tau, \tau_{M}\right)^{\prime} X_{\tau}+C\left(\tau, \tau_{M}\right)\right)
$$

where $B\left(\tau, \tau_{M}\right)$ and $C\left(\tau, \tau_{M}\right)$ are the solutions of the system of ordinary differential equations

$$
\begin{aligned}
\frac{d B\left(\tau, \tau_{M}\right)}{d \tau} & =\rho_{1}+\left(K^{Q}\right)^{\prime} B\left(\tau, \tau_{M}\right) \\
& -\frac{1}{2} \sum_{j=1}^{n}\left(\Sigma^{\prime} B\left(\tau, \tau_{M}\right) B\left(\tau, \tau_{M}\right)^{\prime} \Sigma\right)_{j, j}\left(\delta^{j}\right)^{\prime} \\
\frac{d C\left(\tau, \tau_{M}\right)}{d \tau} & =\rho_{0}-B\left(\tau, \tau_{M}\right)^{\prime} K^{Q} \Theta^{Q} \\
& -\frac{1}{2} \sum_{j=1}^{n}\left(\Sigma^{\prime} B\left(\tau, \tau_{M}\right) B\left(\tau, \tau_{M}\right)^{\prime} \Sigma\right)_{j, j} \gamma^{j}
\end{aligned}
$$

subject to the initial conditions

$$
\begin{aligned}
& B\left(\tau_{M}, \tau_{M}\right)=0 \\
& C\left(\tau_{M}, \tau_{M}\right)=0 .
\end{aligned}
$$

Therefore, the zero-coupon yield function derived from the price function is

$$
\begin{aligned}
s\left(\tau, \tau_{M}\right) & =-\frac{1}{\tau_{M}-\tau} \log P\left(\tau, \tau_{M}\right) \\
& =-\frac{B\left(\tau, \tau_{M}\right)^{\prime}}{\tau_{M}-\tau} X_{\tau}-\frac{C\left(\tau, \tau_{M}\right)}{\tau_{M}-\tau} .
\end{aligned}
$$

and we can decompose the yield function as a three-factor affine model with $X_{\tau}=\left(X_{\tau}^{1}, X_{\tau}^{2}, X_{\tau}^{3}\right)$ almost matching the Nelson-Siegel yield curve model as

$$
\begin{aligned}
s\left(\tau, \tau_{M}\right) & =X_{\tau}^{1}+\frac{1-e^{-\lambda\left(\tau_{M}-\tau\right)}}{\lambda\left(\tau_{M}-\tau\right)} X_{\tau}^{2} \\
& +\left[\frac{1-e^{-\lambda\left(\tau_{M}-\tau\right)}}{\lambda\left(\tau_{M}-\tau\right)}-e^{-\lambda\left(\tau_{M}-\tau\right)}\right] X_{\tau}^{3}-\frac{C\left(\tau, \tau_{M}\right)}{\tau_{M}-\tau},
\end{aligned}
$$

with ODEs for the $B\left(\tau, \tau_{M}\right)$ functions that have solutions

$$
\begin{aligned}
& B^{1}\left(\tau, \tau_{M}\right)=-\left(\tau_{M}-\tau\right) \\
& B^{2}\left(\tau, \tau_{M}\right)=-\frac{1-e^{-\lambda\left(\tau_{M}-\tau\right)}}{\lambda}, \\
& B^{3}\left(\tau, \tau_{M}\right)=\left(\tau_{M}-\tau\right) e^{-\lambda\left(\tau_{M}-\tau\right)}-\frac{1-e^{-\lambda\left(\tau_{M}-\tau\right)}}{\lambda} .
\end{aligned}
$$

We can reformulate Equation 2.5 using loading functions from dynamic Nelson-Siegel model in 
Equation 2.4 as

$$
\begin{aligned}
s\left(\tau, \tau_{M}\right)=X_{\tau}^{1} L_{1}\left(\tau_{M}-\tau\right) & +X_{\tau}^{2} L_{2}\left(\tau_{M}-\tau\right) \\
& +X_{\tau}^{3} L_{3}\left(\tau_{M}-\tau\right)-\frac{C\left(\tau, \tau_{M}\right)}{\tau_{M}-\tau} .
\end{aligned}
$$

The previous formulation almost match the Nelson-Siegel yield curve model except by the yieldadjustment term $-\frac{C\left(\tau, \tau_{M}\right)}{\tau_{M}-\tau}$. Christensen et al. [CDR11] identified the AFNS models fixing the mean levels of the state variable under the Q-measure at zero, i.e., $\Theta^{Q}=0$. Thus, the yield-adjustment term will have the form

$$
-\frac{C\left(\tau, \tau_{M}\right)}{\tau_{M}-\tau}=-\frac{1}{2} \frac{1}{\tau_{M}-\tau} \sum_{j=1}^{3} \int_{\tau}^{\tau_{M}}\left(\Sigma^{\prime} B\left(s, \tau_{M}\right) B\left(s, \tau_{M}\right)^{\prime} \Sigma\right)_{j, j} d s .
$$

Considering a general volatility matrix (not related to the dynamic model for forecasting the yield curve)

$$
\Sigma=\left(\begin{array}{lll}
\sigma_{11} & \sigma_{12} & \sigma_{13} \\
\sigma_{21} & \sigma_{22} & \sigma_{23} \\
\sigma_{31} & \sigma_{32} & \sigma_{33}
\end{array}\right)
$$

Christensen et al. [CDR11] shows that an analytical form of the yield-adjustment term can be derived as

$$
\begin{aligned}
\frac{C\left(\tau, \tau_{M}\right)}{\tau_{M}-\tau} & =\frac{1}{2} \frac{1}{\tau_{M}-\tau} \int_{\tau}^{\tau_{M}} \sum_{j=1}^{3}\left(\Sigma^{\prime} B\left(s, \tau_{M}\right) B\left(s, \tau_{M}\right)^{\prime} \Sigma\right)_{j, j} d s \\
& =\bar{A} \frac{\left(\tau_{M}-\tau\right)^{2}}{6} \\
& +\bar{B}\left[\frac{1}{2 \lambda^{2}}-\frac{1}{\lambda^{3}} \frac{1-e^{-\lambda\left(\tau_{M}-\tau\right)}}{\tau_{M}-\tau}+\frac{1}{4 \lambda^{3}} \frac{1-e^{-2 \lambda\left(\tau_{M}-\tau\right)}}{\tau_{M}-\tau}\right] \\
& +\bar{C}\left[\frac{1}{2 \lambda^{2}}+\frac{1}{\lambda^{2}} e^{-\lambda\left(\tau_{M}-\tau\right)}-\frac{1}{4 \lambda}\left(\tau_{M}-\tau\right) e^{-2 \lambda\left(\tau_{M}-\tau\right)}\right. \\
& \left.-\frac{3}{4 \lambda^{2}} e^{-2 \lambda\left(\tau_{M}-\tau\right)}-\frac{2}{\lambda^{3}} \frac{1-e^{-\lambda\left(\tau_{M}-\tau\right)}}{\tau_{M}-\tau}+\frac{5}{8 \lambda^{3}} \frac{1-e^{-2 \lambda\left(\tau_{M}-\tau\right)}}{\tau_{M}-\tau}\right] \\
& +\bar{D}\left[\frac{1}{2 \lambda}\left(\tau_{M}-\tau\right)+\frac{1}{\lambda^{2}} e^{-\lambda\left(\tau_{M}-\tau\right)}-\frac{1}{\lambda^{3}} \frac{1-e^{-\lambda\left(\tau_{M}-\tau\right)}}{\tau_{M}-\tau}\right] \\
& +\bar{E}\left[\frac{3}{\lambda^{2}} e^{-\lambda\left(\tau_{M}-\tau\right)}+\frac{1}{2 \lambda}\left(\tau_{M}-\tau\right)+\frac{1}{\lambda}\left(\tau_{M}-\tau\right) e^{-\lambda\left(\tau_{M}-\tau\right)}\right. \\
& \left.-\frac{3}{\lambda^{3}} \frac{1-e^{-\lambda\left(\tau_{M}-\tau\right)}}{\tau_{M}-\tau}\right] \\
& +\bar{F}\left[\frac{1}{\lambda^{2}}+\frac{1}{\lambda^{2}} e^{-\lambda\left(\tau_{M}-\tau\right)}-\frac{1}{2 \lambda^{2}} e^{-2 \lambda\left(\tau_{M}-\tau\right)}\right. \\
& \left.-\frac{3}{\lambda^{3}} \frac{1-e^{-\lambda\left(\tau_{M}-\tau\right)}}{\tau_{M}-\tau}+\frac{3}{4 \lambda^{3}} \frac{1-e^{-2 \lambda\left(\tau_{M}-\tau\right)}}{T-t}\right],
\end{aligned}
$$


where

$$
\begin{aligned}
& \bar{A}=\sigma_{11}^{2}+\sigma_{12}^{2}+\sigma_{13}^{2} \\
& \bar{B}=\sigma_{21}^{2}+\sigma_{22}^{2}+\sigma_{23}^{2} \\
& \bar{C}=\sigma_{31}^{2}+\sigma_{32}^{2}+\sigma_{33}^{2} \\
& \bar{D}=\sigma_{11} \sigma_{21}+\sigma_{12} \sigma_{22}+\sigma_{13} \sigma_{23} \\
& \bar{E}=\sigma_{11} \sigma_{31}+\sigma_{12} \sigma_{32}+\sigma_{13} \sigma_{33} \\
& \bar{F}=\sigma_{21} \sigma_{31}+\sigma_{22} \sigma_{32}+\sigma_{23} \sigma_{33} .
\end{aligned}
$$

For the Independent-Factors AFNS model, Christensen et al. estimated the general volatility matrix as

$$
\hat{\Sigma}=\left(\begin{array}{ccc}
0.0051 & 0 & 0 \\
0 & 0.0110 & 0 \\
0 & 0 & 0.0264
\end{array}\right)
$$

and $\hat{\lambda}=0.5975$ for maturities measured in years, solving the yield-adjustment equation for arbitragefree condition.

Note that the adjustment-term of AFNS model is time-independent. In other words, it is a deterministic function which depends only on the maturity of the bond. So, let the function $\Gamma(\tau)$ be

$$
\Gamma(\tau)=-\frac{C(0, \tau)}{\tau} .
$$

As in the Dynamic Nelson-Siegel model, the Dynamic Arbitrage-Free Nelson-Siegel model describes the Arbitrage-Free Nelson-Siegel static model evolving over time. The specification is

$$
\begin{aligned}
s_{t}(\tau) & =\beta_{1, t} L_{1}(\tau)+\beta_{2, t} L_{2}(\tau)+\beta_{3, t} L_{3}(\tau)+\Gamma(\tau)+\epsilon_{t} \\
t & =1, \ldots, T
\end{aligned}
$$

where the loadings are the usual functions of Equation 2.4.

The parameter $\lambda$ will assume the estimated value $\hat{\lambda}=0.5975$. It has the same interpretation of dynamic Nelson-Siegel model as a conductor of the curve exponential decay rate. Also, the coefficients $\beta_{i, t}$ are $\mathrm{AR}(1)$ processes described as

$$
\beta_{i, t}=c_{i}+\phi_{i} \beta_{i, t}+\eta_{i, t} \quad i=1,2,3
$$

where the intercepts $c_{i}$, the parameters $\phi_{i}$ and the coefficients $\beta_{i, t}$ are obtained fitting the model over a dataset of $T$ daily market observations. Furthermore, $\epsilon_{t} \sim \mathcal{N}\left(0, \sigma_{\epsilon}^{2}\right)$ and $\eta_{i, t} \sim \mathcal{N}\left(0, \sigma_{i}^{2}\right)$ are independent errors. Since the yield curve model depends only on $\beta_{1, t}, \beta_{2, t}, \beta_{3, t}$, forecasting the yield curve is equivalent to forecasting $\beta_{1, t}, \beta_{2, t}, \beta_{3, t}$. 


\section{Chapter 3}

\section{Dynamic Constrained Smoothing B-splines}

Constrained Smoothing B-Splines is a methodology first proposed by He and Shi[HS98] and then formalized by $\mathrm{He}$ and $\mathrm{Ng}[\mathrm{HN} 99]$ as a proper algorithm. It extends smoothing splines to a conditional quantile function estimation and then formulates the fitting model into a linear programming problem that can incorporate constraints such as monotonicity, convexity and boundary conditions.

Laurini and Moura [LM10] applied this methodology as a static model to fit daily yield curves along with no-arbitrage constraints. The estimation of the daily term structure of interest rates is set to be a conditional median estimation that is robust to outliers. This model produces yield curves as $L_{1}$ projection into the space of B-splines. The flexible nature of B-splines by its local support and the constraints of the model can make the curve fit the data according to its financial meaning and carrying with it all possible information.

Our contribution in this paper is a Dynamic Constrained Smoothing B-splines model that describes the static model evolving over time.

The dynamic model, DCOBS, is estimated by the Penalized Least Absolute Deviation

$$
\min _{\theta \in \mathbb{R}^{C}} \sum_{i=1}^{n}\left|y_{i}-\sum_{j=1}^{C} a_{j} B_{j}\left(\tau_{i}\right)\right|+\Lambda \max _{\tau} \sum_{i=1}^{C} a_{j}\left(B_{j}(\tau)\right)^{\prime \prime},
$$

where $n$ is the number of contracts available in the reference day, $y_{i}$ are market yields of the contracts, $C=N+m$ is the number of coefficients, $N$ is the number of internal knots, $m=3$ is the order for quadratic B-Splines basis, $\theta=\left(a_{1}, \ldots, a_{C}\right)$ is the coefficient vector to be estimated, $B_{j}$ are the quadratic B-splines basis and $\tau_{i}$ are distinct maturities of the contracts. The selection of the smoothing parameter $\Lambda$ is automated with generalized cross validation (Leave-One-Out GCV) method of [FNZ95 $]^{1}$.

The previous formulation can be rewritten as

$$
\min _{\theta \in \mathbb{R}^{C}} \sum_{i=1}^{n}\left|y_{i}-\sum_{j=1}^{C} a_{j} B_{j}\left(\tau_{i}\right)\right|+\Lambda \omega
$$

such that

$$
-\omega \leq \sum_{j=1}^{C} a_{j}\left(B_{j}\left(t_{k}\right)\right)^{\prime \prime} \leq \omega
$$

where $k=1, \ldots, N$ and $t_{k}$ is an internal knot position.

\footnotetext{
${ }^{1} \mathrm{GCV}$ is "Leave-One-Out" cross validation technique where the curve is fitted leaving one sample out, and then calling the best parameter $\Lambda$ with all samples considered.
} 
The above static model can be implemented as an equivalent linear programming problem that minimizes the objective function $z$ such that

$$
\min z=\sum_{i=1}^{n}\left|e_{i}\right|+|\omega| .
$$

Each yield observed in the market will produce five linear constraint equations: two constraints for fitting the curve, one constraint for smoothing and two constraints for no-arbitrage conditions.

The fitting constraints are

$$
\begin{aligned}
& \sum_{j=1}^{C} a_{j} B_{j}\left(\tau_{i}\right)+\left|e_{i}\right| \geq y_{i} \\
& \sum_{j=1}^{C} a_{j} B_{j}\left(\tau_{i}\right)-\left|e_{i}\right| \leq y_{i}
\end{aligned}
$$

where all $B_{j}\left(\tau_{i}\right)$ are quadratic B-spline basis.

The smoothing constraint is

$$
\Lambda \sum_{j=1}^{C} a_{j}\left(B_{j}\left(\tau_{i}\right)\right)^{\prime \prime}-|\omega| \leq 0 .
$$

Finally, the no-arbitrage constraints are

$$
\begin{aligned}
& \sum_{j=1}^{C} a_{j} B_{j}\left(\tau_{i}\right)>0 \\
& \sum_{j=1}^{C} a_{j}\left(B_{j}\left(\tau_{i}\right)\right)^{\prime}<0 .
\end{aligned}
$$

The resulting fitted yield curve,

$$
\hat{s}(\tau)=\sum_{j=1}^{C} \hat{a}_{j} B_{j}(\tau)
$$

is a conditional median function represented by quadratic smoothing B-splines.

We proposed the Dynamic Constrained Smoothing B-Splines model as

$$
\begin{aligned}
s_{t}(\tau) & =\sum_{j=1}^{C} a_{j, t} B_{j}(\tau)+\epsilon_{t} \\
t & =1, \ldots, T
\end{aligned}
$$

where the coefficients $a_{j, t}$ are $\mathrm{AR}(1)$ processes described as

$$
a_{j, t}=c_{j}+\phi_{j} a_{j, t-1}+\eta_{j, t} \quad j=1 \ldots C
$$

where the intercepts $c_{j}$, the parameters $\phi_{j}$ and the coefficients $a_{j, t}$ are obtained fittin the model over a dataset of $T$ daily market observations. Furthermore, $\epsilon_{t} \sim \mathcal{N}\left(0, \sigma_{\epsilon}^{2}\right)$ and $\eta_{j, t} \sim \mathcal{N}\left(0, \sigma_{j}^{2}\right)$ are independent errors. Since the yield curve model depends only on $a_{j, t}$, forecasting the yield curve is equivalent to forecasting $a_{j, t}$.

The Dynamic Constrained Smoothing B-Splines model describes the static model evolving over time. In other words, the dynamic model extrapolates the temporal axis creating a surface of fitted 
curves.

Figure 3.1 gives us a visual idea of the differences between each yield curve model.

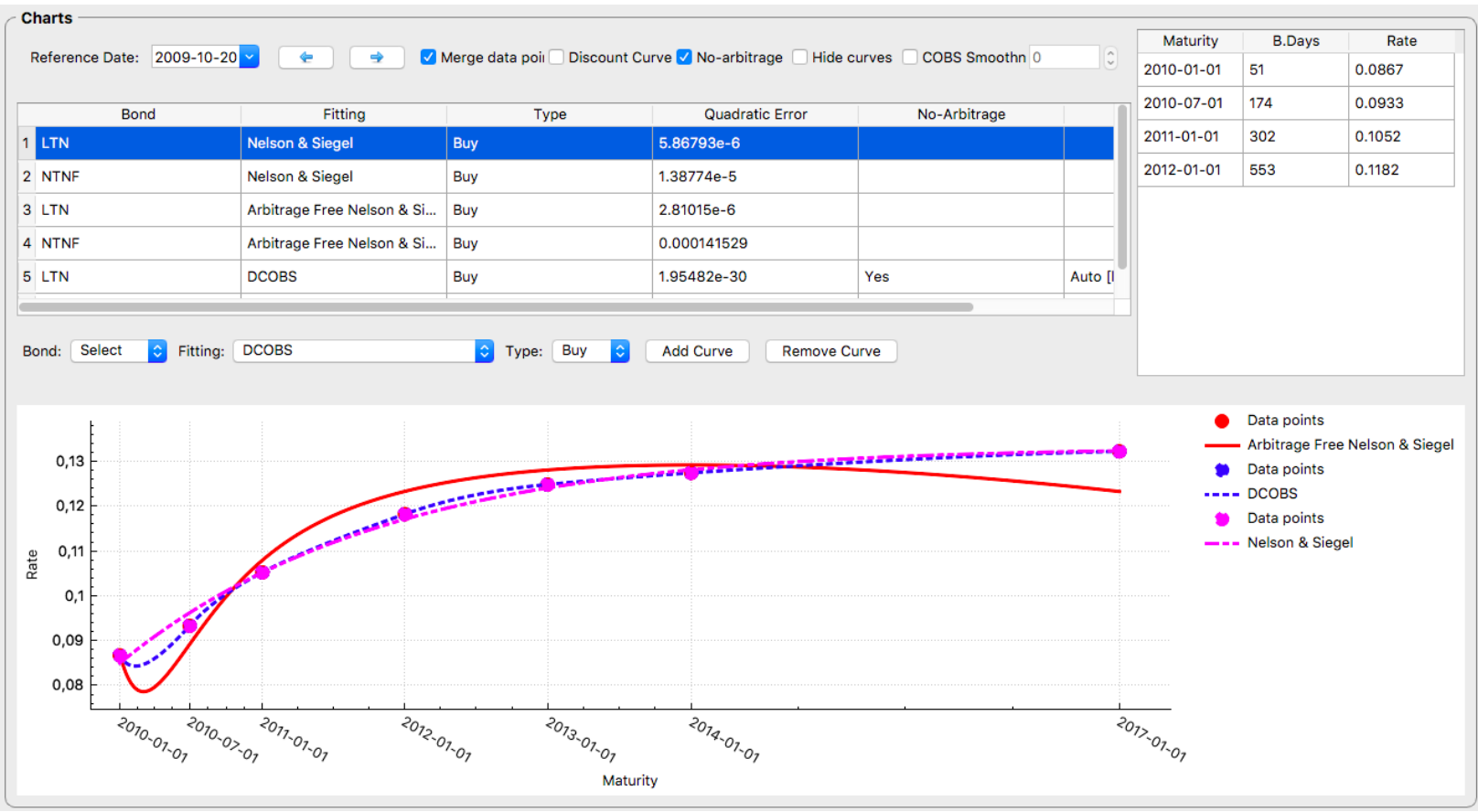

Figure 3.1: Yield curves for term structure at 2009-10-20 


\section{Chapter 4}

\section{Descriptive Analysis}

This work used 10 years (2006-2016) of public historical data of brazilian government bonds LTN and NTN-F. The buying prices were used in this paper. The period of 2006-2015 was designed as sample data and 2016 was designed as test data.

LTN is a short-term fixed income zero-coupon bond considered risk-free. NTN-F is a mediumterm fixed income coupon-bearing bond that pays $10 \%$ of the principal semiannually. We extracted the zero-coupon equivalent rates from NTN-F through financial bootstrapping procedure ${ }^{1}$ so it was possible to merge data points from the two bonds and get a larger yield curve horizon.

The sample data is constituted of 20.604 data points in 2.500 reference dates spanning between 2006-01-02 and 2015-12-31. The term structure horizon spans between 1 business day and 2.744 business days. The sample data set originated 5.000 yield curves, being 2.500 AFNS and 2.500 DCOBS. By the nature of parametric models, there is no challenge in relating the coefficients in a time-dependent process. So, Arbitrage-Free Nelson-Siegel yield curves are fitted using the raw sample data.

On the other hand, nonparametric B-Splines model depends on its knots and data points position. Therefore, a two-step normalization procedure was applied so the coefficients could be related in a time-dependent process. The first step normalizes the horizon length. The internal knots are defined as $K_{\text {int }}=(126,1260)$ and the boundary knots as $K_{\text {bnd }}=(0,2745)$, based on observed data and the overall fitting quality it produced. This definition implied a term structure of 5 knots $^{2}$. Since B-Splines can not be used for extrapolation, since its basis are zero outside their definitions, we used Nelson-Siegel model to extrapolate the horizon and calculate the yields on the boundaries of the term structure. The second step normalizes the data points position. This time, we build a curve with DCOBS with knots being equally distributed across the horizon. With the resulting fitted curve, we calculate the final normalized term structure at previously selected points $(0, s(126), s(567), s(1260), s(2745))$.

For instance, consider the term structure of interest rates as in 2013-01-02 in Table 4.1.

Fitting this term structure with Nelson-Siegel model produces a term structure with yields at the boundaries as shown in Table 4.2 .

Finally, fitting the resulting term structure with constrained smoothing B-Splines and knots distributed equally across the horizon, a normalized term structure is obtained as shown in Table 4.3 .

\footnotetext{
${ }^{1}$ Bootstrapping is an iterative procedure that creates an equivalent zero-coupon bond from a coupon-bearing bond. This is achieved by looking in he market for zero-coupon bonds with maturities equal to the maturities of future coupon payments. The zero-coupon bond interest rates is than related to the future coupon payments of the coupon-bearing bonds. The resulting zero-coupon bonds will be equivalent to the coupon-bearing bonds with its coupon payments translated and summed to one single final payment.

${ }^{2}$ For more information: https://goo.gl/z4C9Dz
} 


\begin{tabular}{|c|c|}
\hline Business Days & Yield \\
\hline \hline 253 & 0.0715751 \\
\hline 506 & 0.0775 \\
\hline 756 & 0.0825 \\
\hline 1007 & 0.0867064 \\
\hline 2010 & 0.0975515 \\
\hline 2512 & 0.100645 \\
\hline
\end{tabular}

Table 4.1: Term Structure as in 2013-01-02.

\begin{tabular}{|c|c|}
\hline Business Days & Yield \\
\hline \hline 1 & 0.06495709 \\
\hline 253 & 0.0715751 \\
\hline 506 & 0.0775 \\
\hline 756 & 0.0825 \\
\hline 1007 & 0.0867064 \\
\hline 2010 & 0.0975515 \\
\hline 2512 & 0.100645 \\
\hline 2745 & 0.101758 \\
\hline
\end{tabular}

Table 4.2: Term structure with yields at the boundaries.

\begin{tabular}{|c|c|}
\hline Business Days & Yield \\
\hline \hline 0 & 0 \\
\hline 126 & 0.0686091 \\
\hline 567 & 0.0788766 \\
\hline 1260 & 0.0903086 \\
\hline 2745 & 0.101758 \\
\hline
\end{tabular}

Table 4.3: Normalized term structure. 


\section{Chapter 5}

\section{Results}

We have generated a normalized data set with 12.500 data points which are the inputs for the yield curves. The procedure we proposed in DCOBS to normalize daily term structures and create a temporal relationship between coefficients certainly imply loss of information. However, the resulting yield curves had a better performance compared to AFNS considering $\mathrm{RMSE}^{1}$ in every year of sample data set as shown in Table 5.1. The difference of fitting between both methods can be seen in Figure 5.1.

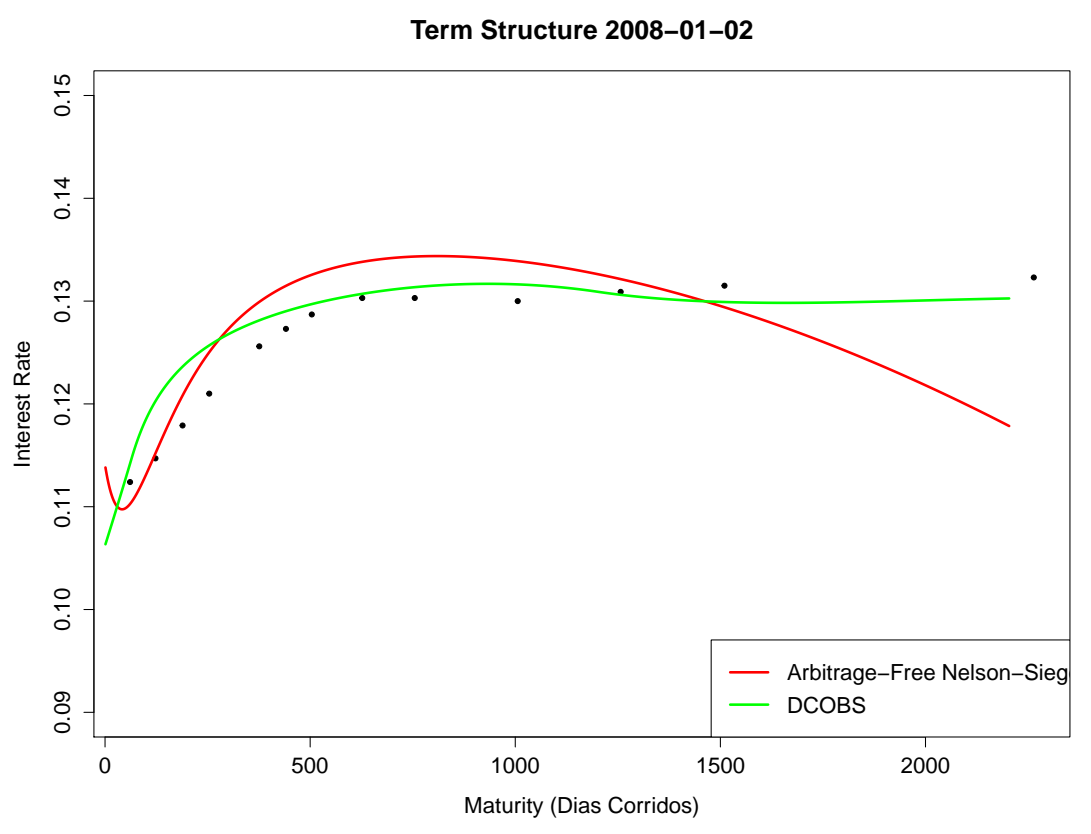

Figure 5.1: DCOBS compared to AFNS

We fitted 2.500 yield curves for both methods AFNS and DCOBS. For each curve, the method AFNS produced three coefficients and DCOBS produced five coefficients.

The first coefficient of AFNS model shows a stable behaviour, however the second and third keep its stability until the business day 1.000 , where it becomes unstable. In one day, the second coefficient goes from -0.0203354 to 4.73094 between 2011-12-30 and 2012-01-02. Analogously, the third coefficient goes from -0.155503 to -5.0988 , compensating the jump of second coefficient. This behaviour repeats for reference dates 2012-12-28, 2013-12-27 and 2014-12-31. Figure 5.2 shows the three series of AFNS coefficients.

We concluded that this behaviour reveals a sensibility of AFNS approach to the number of contracts available in the market. Taking into account the reference date 2011-12-30 (1.497 business days), there were six contracts available against five contracts at 2012-01-02, the next business day.

\footnotetext{
${ }^{1}$ Root Mean Square Error
} 


\begin{tabular}{|c|c|c|}
\hline Year & DCOBS RMSE & AFNS RMSE \\
\hline \hline 2006 & 0.012265 & 0.021373 \\
\hline 2007 & 0.016608 & 0.054421 \\
\hline 2008 & 0.029025 & 0.045070 \\
\hline 2009 & 0.042418 & 0.047167 \\
\hline 2010 & 0.015881 & 0.047804 \\
\hline 2011 & 0.010699 & 0.033103 \\
\hline 2012 & 0.008795 & 0.059564 \\
\hline 2013 & 0.013845 & 0.026148 \\
\hline 2014 & 0.011540 & 0.040362 \\
\hline 2015 & 0.009979 & 0.025593 \\
\hline Total & 0.171055 & 0.400605 \\
\hline
\end{tabular}

Table 5.1: RMSE fitting errors.
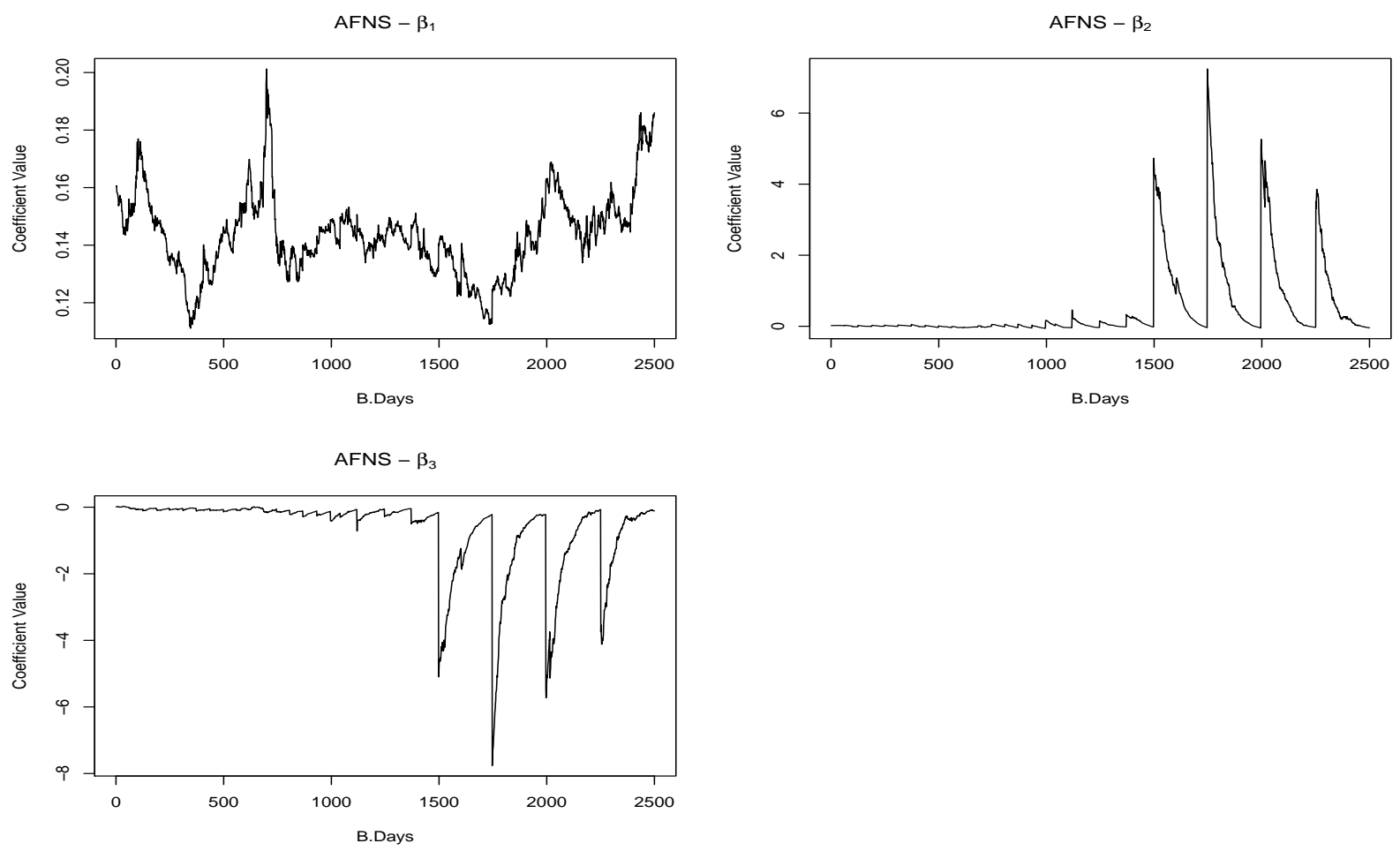

Figure 5.2: AFNS Coefficient Series

\begin{tabular}{|c|c|}
\hline Parameter & test-statistic \\
\hline \hline$\beta_{1}$ & -36.3622 \\
\hline$\beta_{2}$ & -35.555 \\
\hline$\beta_{3}$ & -35.5626 \\
\hline
\end{tabular}

Table 5.2: AFNS ADF Test for coefficients

Using the Augmented Dickey-Fuller Test [DF79], we see that the three series are $I(1)$, or in other words, applying one order of differentiation the series become stationary, considering a $1 \%$ critical value of -2.58 . Since all tests are lower than the critical value, we then reject the unitary root null hypothesis $\pi=0$. Table 5.2 shows ADF test statistics for AFNS coefficients with one order of differentiation.

In Figure 5.2 we see that $\beta_{2}$ and $\beta_{3}$ may be cointegrated, so we run a two-step Engle-Granger 
cointegration test [EG87]. The linear regression of $\beta_{3}$ explained by $\beta_{2}$ returned an intercept of -0.144433 and a coefficient of -1.079191 . The cointegration test over linear regression residuals returned a statistic of -3.6481 , which in turn confronted with the critical values of Table 2 in [EY87] leads us to reject the unitary root hypothesis because the residuals are stationary. The conclusion is that there is a cointegration between $\beta_{2}$ and $\beta_{3}$. Figure 5.3 shows $\beta_{3}$ estimated by $\beta_{2}$ through linear regression.

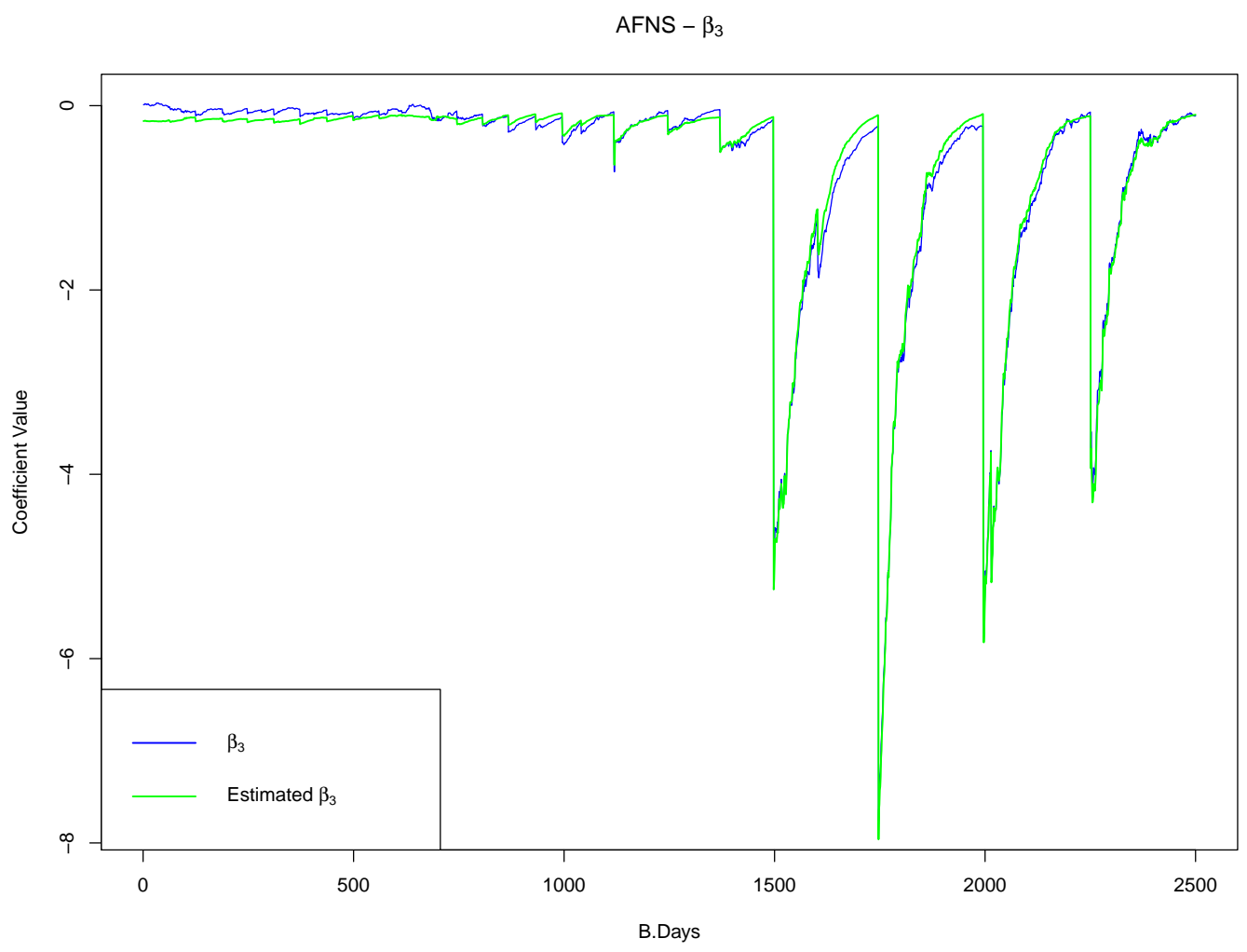

Figure 5.3: $\beta_{3}$ estimated by $\beta_{2}$
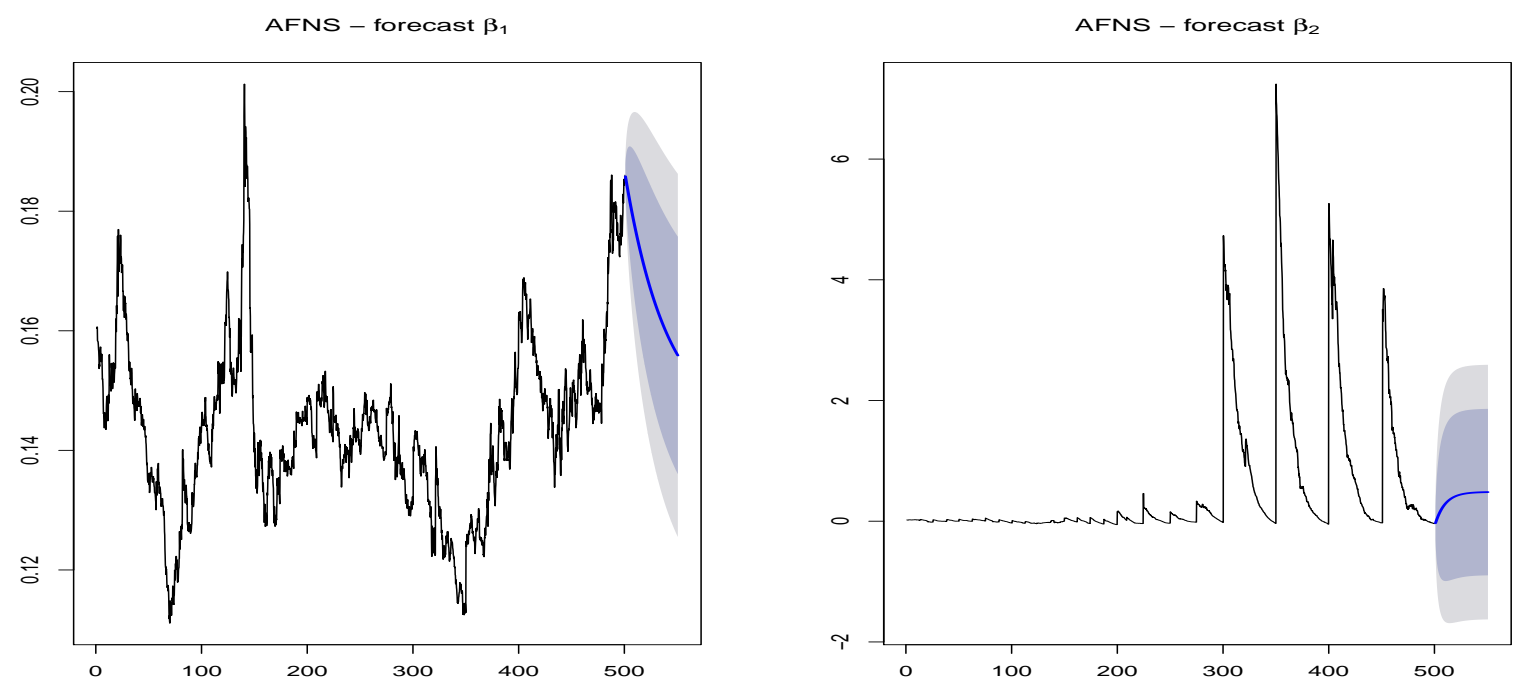

Figure 5.4: AFNS coefficient time series

The time series for $\beta_{1}$ and $\beta_{2}$ are modeled as $\operatorname{AR}(1)$ processes. The coefficient $\phi$ of the time series for $\beta_{1}$ is 0.0302 and for $\beta_{2}$ is -0.0095 . Figure 5.4 shows the forecast for both $\beta_{1}$ and $\beta_{2}$. 
The first coefficient of DCOBS model keeps constant at 1.0 for all fitted curve. Therefore, we did not create a time serie for this coefficient. Except for a few outliers, the time series for all DCOBS coefficients have a very stable behaviour. The time series for DCOBS coefficients can be seen in Figure 5.5.
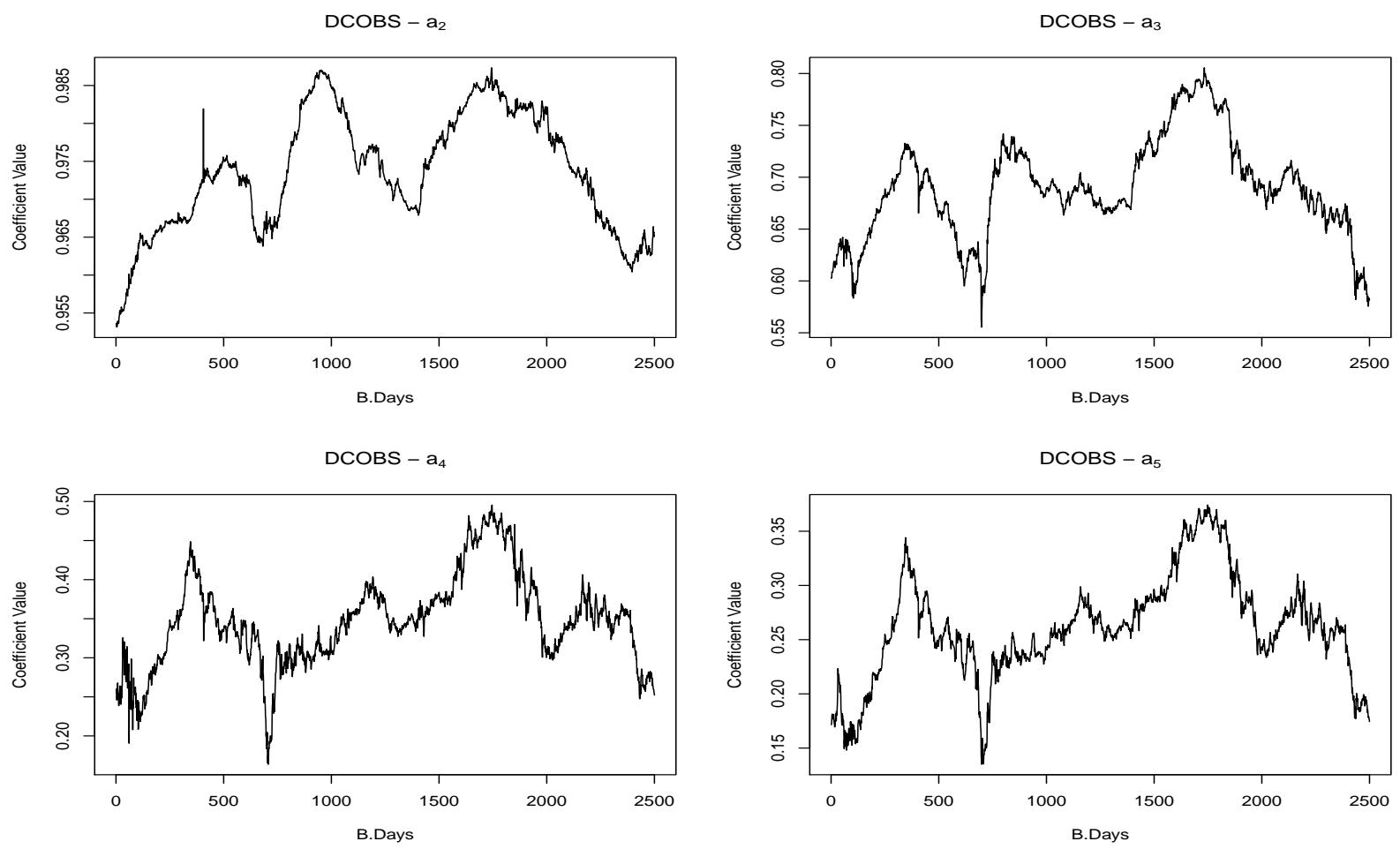

Figure 5.5: DCOBS Coefficient Series

The Augmented Dickey-Fuller Test shows that the four series are $I(1)$, or in other words, applying one order of differentiation the series become stationary, considering a $1 \%$ critical value of -2.58 . Since all tests are lower than the critical value, we then reject the unitary root null hypothesis $\pi=0$. Table 5.3 shows ADF test statistics for DCOBS coefficients with one order of differentiation.

\begin{tabular}{|c|c|}
\hline Parameter & test-statistic \\
\hline \hline$a_{2}$ & -41.9694 \\
\hline$a_{3}$ & -35.8711 \\
\hline$a_{4}$ & -39.9662 \\
\hline$a_{5}$ & -35.5342 \\
\hline
\end{tabular}

Table 5.3: DCOBS ADF Test for coefficients

As seen in AFNS coefficients time series, DCOBS coefficients $a_{4}$ and $a_{5}$ seems to cointegrate, so we run a two-step Engle-Granger cointegration test. The linear regression of $a_{5}$ explained by $a_{4}$ returned an intercept of -0.018051 and a coefficient of 0.803629 . The cointegration test over linear regression residuals returned a statistic of -7.7799 , which in turn confronted with the critical values of Table 2 in [EY87] leads us to reject the unitary root hypothesis because the residuals are stationary. The conclusion is that there is a cointegration between $a_{4}$ and $a_{5}$. Figure 5.6 shows $a_{5}$ estimated by $a_{4}$.

The time series for $a_{2}, a_{3}$ and $a_{4}$ are modeled as $\operatorname{AR}(1)$ processes. The coefficient $\phi$ of the time series for $a_{2}$ is $0.9991, a_{3}$ is 0.9986 and for $a_{4}$ is 0.9932 . Figure 5.7 shows the forecast for all coefficients.

The time series above modeled as $\mathrm{AR}(1)$ processes were used to make the out-of-sample forecast 


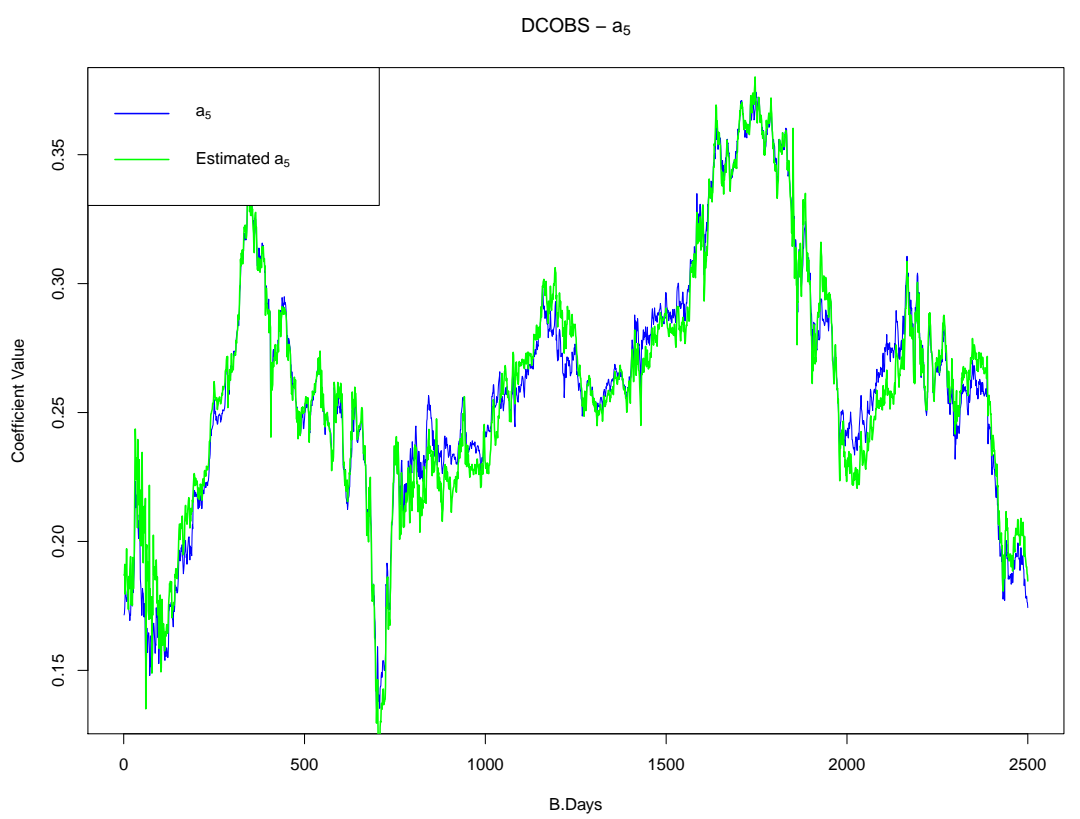

Figure 5.6: $a_{5}$ estimated by $a_{4}$
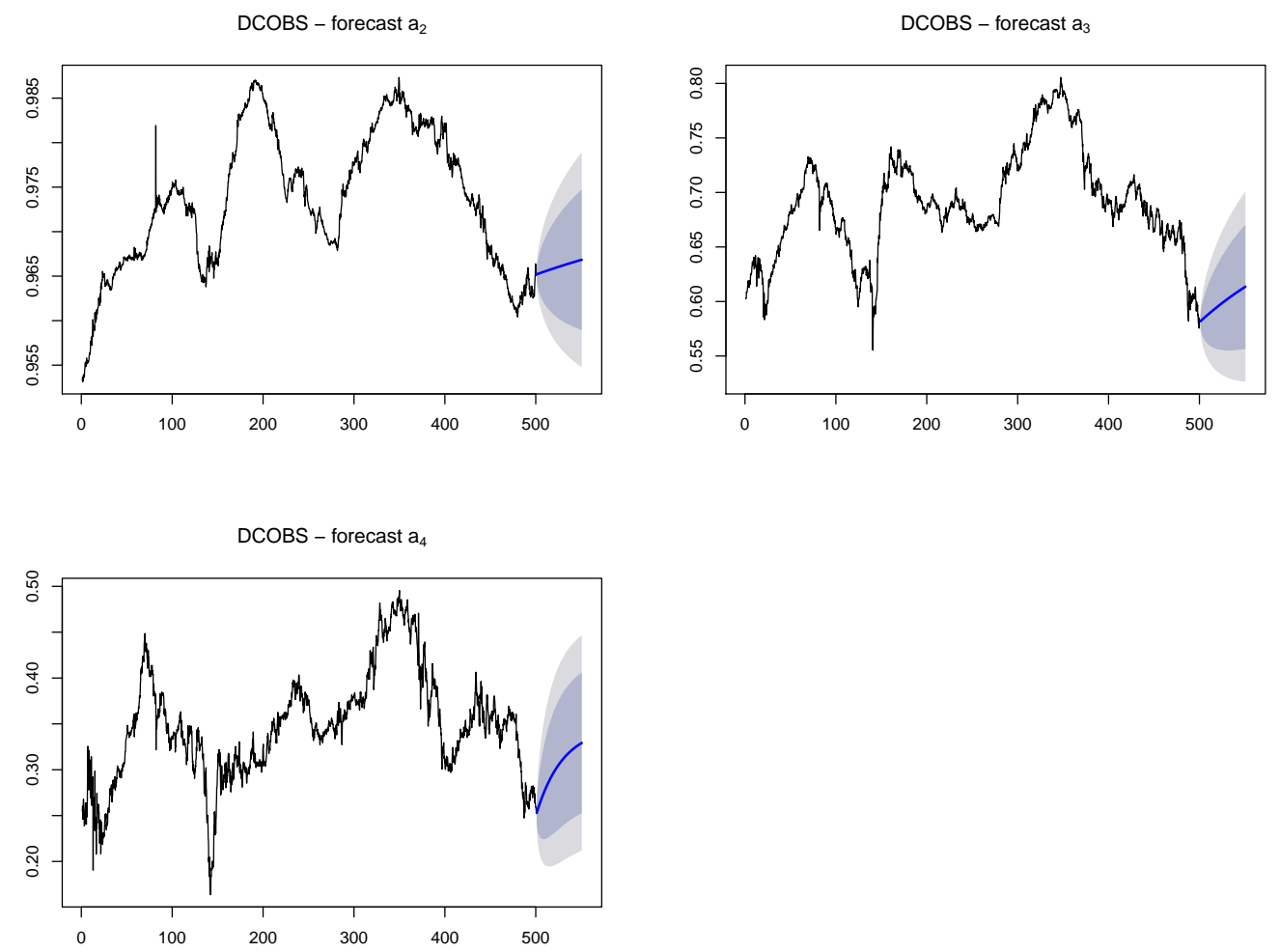

Figure 5.7: DCOBS coefficient time series

with horizon of 249 business days, the amount of business days in test dataset of 2016. Three reference dates were considered to evaluation: 1 month, 6 months and 12 months. Figure 5.8 shows the forecast curves.

In 1-month forecast, DCOBS performs a good fit to the term structure, specially in long-term horizon, as the curve follows the data points. AFNS shows a heavy instability in short-term horizon, although in long-term it regains stability. In both 6-months and 12-months forecasts, AFNS and 


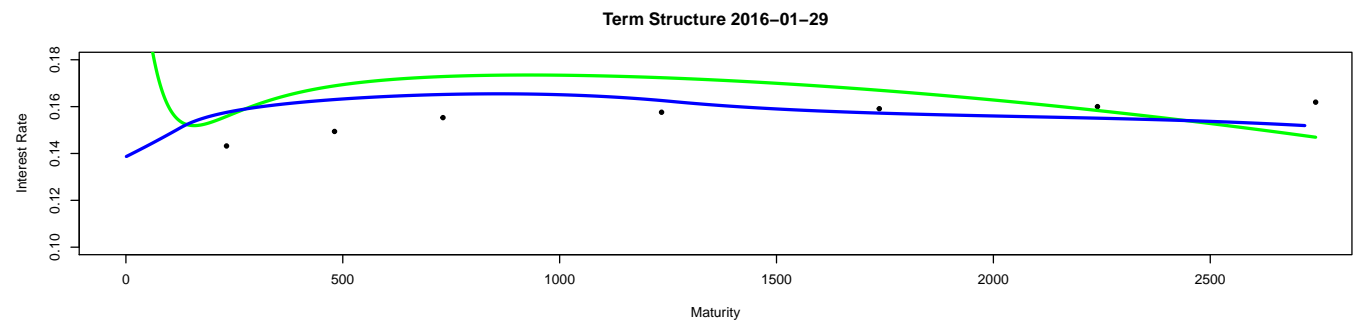

Term Structure 2016-06-30

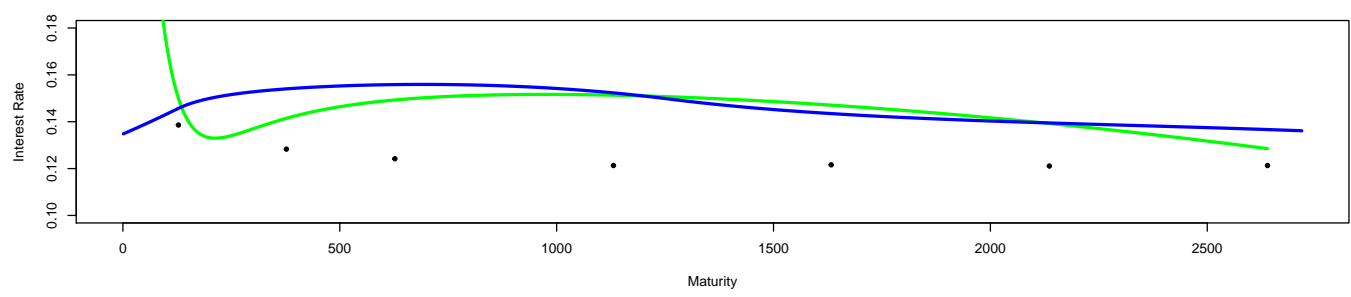

Term Structure 2016-12-29

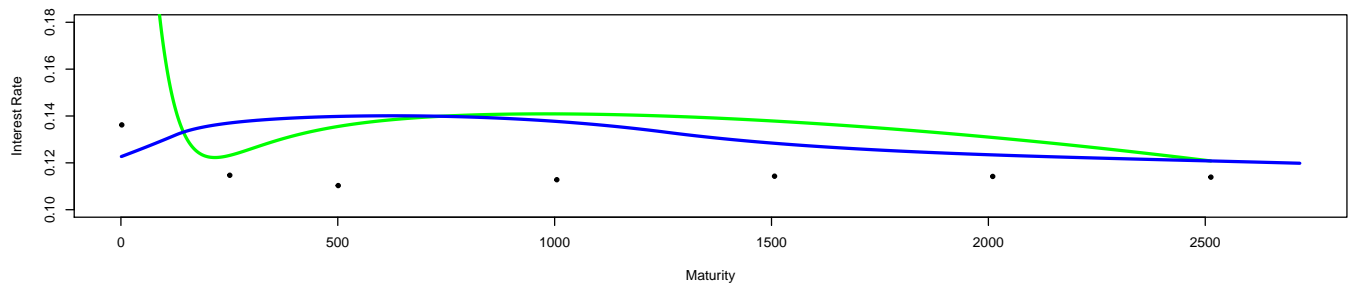

Figure 5.8: Forecast results

DCOBS methods remained between $12.5 \%$ and $14 \%$, while the term structure decreased from $14 \%$ to $11 \%$ in long-term horizon. AFNS also diverged in 12-months forcast at short-term and produced almost $30 \%$ of root mean square error.

We compared both forecast techniques through Diebold-Mariano accuracy test[DM95] with alternative hypothesis being DCOBS outperforming AFNS prediction. As we stated before, DCOBS outperforms AFNS in the short-term prediction. The absolute value of Diebold-Mariano statistics for 1-month forecast is greated than 1.96, so we reject the null hypothesis that both techniques have the same accuracy. On the other hand, for 6-months and 12-months forecast, the absolute value of Diebold-Mariano statistics keeps lower than 1.96, which means that we do no reject the null hypothesis and both techniques may have the same predictive accuracy. Table 5.4 shows forecasts root mean square errors and Table 5.5 shows Diebold-Mariano statistics results.

\begin{tabular}{|c|c|c|c|}
\hline Method & 1-month & 6-months & 12-months \\
\hline \hline AFNS & 0.044101 & 0.065274 & 0.294319 \\
\hline DCOBS & 0.029812 & 0.075561 & 0.060160 \\
\hline
\end{tabular}

Table 5.4: Forecast root mean square errors

\begin{tabular}{|c|c|c|c|}
\hline Method & 1-month & 6-months & 12-months \\
\hline \hline DM & 2.4671 & -1.3599 & 1.0003 \\
\hline p-value & 0.02432 & 0.8886 & 0.1779 \\
\hline
\end{tabular}

Table 5.5: Diebold-Mariano Test Statistics 


\section{Chapter 6}

\section{Conclusion}

In this work, we have proposed DCOBS, a methodology for forecasting the dynamics of term structure of interest rates based on Constrained Smoothing B-Splines curve fitting. This methodology was composed by five steps:

- Selection of knot positions based on historical data;

- Term structure normalization creating a temporal relationship between DCOBS coefficients;

- Yield curves fitting;

- Time series for curves coefficients;

- Forecast coefficients.

B-Splines knots were fixed at $(0,126,1260,2718)$ based on the distribution of maturity dates on observed data and the overall fitting quality.

The normalization procedure of term structures created a temporal relationship between coefficients with small autocorrelation, making forecast possible. Even though the normalization implied loss of data, the quality of DCOBS fitting was still better than AFNS.

The results have shown a great predictability of DCOBS model on the short-term. This is coherent with Tourrucôo's conclusion that, in long forecast horizons, AFNS model with uncorrelated factors delivers most accurate forecasts [TCMS16]. Even though the accuracy of DCOBS in the longterm are statistically equivalent with AFNS, the stability of the model can be certainly used for future works to improve its predictability quality. 


\section{Bibliography}

[BC01] Luca Barzanti e Corrado Corradi. A note on interest rate term structure estimation by monotonic smoothing splines. Statistica (Bologna), 61(2):205-212, 2001. 2

[CDR11] Jens Christensen, Francis Diebold e Glenn Rudebusch. The affine arbitrage-free class of Nelson-Siegel term structure models. Journal of Econometrics, 164(1):4-20, 2011. 2, 7, 9

[CIR85] John C Cox, Jr Ingersoll, Jonathan E e Stephen A Ross. A theory of the term structure of interest rates. Econometrica, 53(2):385-407, 1985. 6

[DF79] David A. Dickey e Wayne A. Fuller. Distribution of the estimators for autoregressive time series with a unit root. Journal of the American Statistical Association, 74(366):427-431, 1979. 18

[DK96] Darrell Duffie e Rui Kan. A yield-factor model of interest rates. Mathematical Finance, 6(4):379-406, 1996. 2, 6, 7, 8

[DL03] Francis X. Diebold e Canlin Li. Forecasting the term structure of government bond yields. Working Paper 10048, National Bureau of Economic Research, October 2003. 1, 6,7

[DM95] Francis Diebold e Roberto Mariano. Comparing predictive accuracy. Journal of Business and Economic Statistics, 13(3):253-63, 1995. 22

[Duf02] Gregory R. Duffee. Term premia and interest rate forecasts in affine models. The Journal of Finance, 57(1):405-443, 2002. 1, 2

[EG87] Robert Engle e Clive Granger. Co-integration and error correction: Representation, estimation, and testing. Econometrica, 55(2):251-76, 1987. 19

[EY87] Robert Engle e Byung Sam Yoo. Forecasting and testing in co-integrated systems. Journal of Econometrics, 35(1):143-159, 1987. 19, 20

[FNZ95] Mark Fisher, Douglas Nychka e David Zervos. Fitting the term structure of interest rates with smoothing splines. Finance and Economics Discussion Series 95-1, Board of Governors of the Federal Reserve System (U.S.), 1995. 11

[HJM92] David Heath, Robert Jarrow e Andrew Morton. Bond Pricing and the Term Structure of Interest Rates: A New Methodology for Contingent Claims Valuation. Econometrica, 60(1):77-105, January 1992. 6

[HN99] Xuming He e Pin Ng. Cobs: qualitatively constrained smoothing via linear programming. Computational Statistics, 14(3):315-337, 1999. 2, 11

[HS98] Xuming He e Peide Shi. Monotone b-spline smoothing. Journal of the American Statistical Association, 93(442):643-650, 1998. 2, 11 
[HW90] John Hull e Alan White. Pricing interest-rate-derivative securities. Review of Financial Studies, 3(4):573-92, 1990. 6

[KB78] Roger W Koenker e Gilbert Bassett. Regression quantiles. Econometrica, 46(1):33-50, 1978. 2

[LM10] Márcio Laurini e Marcelo Moura. Constrained smoothing b-splines for the term structure of interest rates. Insurance: Mathematics and Economics, 46(2):339-350, 2010. 1, 2, 11

[NS87] Charles Nelson e Andrew F Siegel. Parsimonious modeling of yield curves. The Journal of Business, 60(4):473-89, 1987. 1, 6

[Pia10] Monika Piazzesi. \{CHAPTER\} 12 - affine term structure models. Em Handbook of Financial Econometrics: Tools and Techniques, volume 1 of Handbooks in Finance, páginas 691 - 766. North-Holland, San Diego, 2010. 1

[Sve94] Lars E.O. Svensson. Estimating and interpreting forward interest rates: Sweden 1992 1994. Working Paper 4871, National Bureau of Economic Research, September 1994. 1, 6

[TCMS16] Fabricio Tourrucôo, João F. Caldeira, Guilherme Moura e Andre Santos. Forecasting the yield curve with the Arbitrage-Free dynamic Nelson-Siegel model: Brazilian evidence. Anais do XLII Encontro Nacional de Economia [Proceedings of the 42ndd Brazilian Economics Meeting], ANPEC - Associação Nacional dos Centros de Pós Graduação em Economia [Brazilian Association of Graduate Programs in Economics], 2016. 2, 23

[Vas77] Oldrich Vasicek. An equilibrium characterization of the term structure. Journal of Financial Economics, 5(2):177-188, 1977. 6

[VVT08] Jose Vicente, José Vicente e Benjamin M. Tabak. Forecasting bond yields in the brazilian fixed income market. International Journal of Forecasting, 24(3):490-497, 2008. 7 